\title{
An Examination of Environmental Sanitation and Its Health Hazards in the Polytechnic, Ibadan
}

\author{
Sanni Moronkola Munir \\ Acquisition Unit of The Polytechnic, Ibadan Library, Oyo State, Nigeria \\ Emailmsanni2010@yahoomail.com/msanni2013@gmail.com
}

\section{Doi:10.5901/ajis.2015.v4n1p377}

\begin{abstract}
This paper studies the effects of environmental pollution in the Polytechnic Ibadan, as public issue for sustainable development. Primary data were sourced through survey method of questionnaire. Spot observation of facilities and staff handlers supported the survey. The data sample size of 250 respondents drawn through random sampling technique was adopted. in this order: $12 \%$ were administered to staff at the Health Centre, 20\% to staff of Works and Service Units, and $16 \%$ to staff in other Departments. The remaining $52 \%$ were administered to Students. The data were analyzed using simple descriptive statistical tables and percentages. The secondary data for this work were obtained from Health Centers' documents, literature reviews of related works and text books. The findings of the work revealed that sanitation habit is a way of life in The Polytechnic, Ibadan. This community supported the factor of ensuring a safe and hygienic condition as the reason for consideration with (38\%) response. Other factors such as societal values (32\%) and mass media (40\%) are much more significant to this people than government policies. Also the choice of technological practices is a function of financial capability as it attracted highest attention of $30 \%$ responses. It was noted that academic environment favors this programme than urban settlement because of intellectual innovation and creativity of ideas. However this community put up some identifiable obstacles that hindered proper hygienic practices.
\end{abstract}

Keyword: Environmental pollution, sanitation, human health, hygienic condition, The polytechnic Ibadan.

\section{Introduction}

The Polytechnic, Ibadan came into existence from the relics of old technical education of 1960.The committee inaugurated for its establishment was given the mandate for the establishment of Vocational and Technological Education, which will create rare value for the region within the country at large. The dream then became a reality in 1971.

The Polytechnic, Ibadan was the second polytechnic established after Yaba College of Technology in the SouthWest. Its site was formerly used by Old Technical College in 1950s, the University College of Ibadan (U.C.I.) and later the University of Ife now Obafemi Awolowo University in 1940s, and 1960s, as temporary site respectively. By this The Polytechnic, Ibadan is the second generation categories of Nigerian Academic Institutions with features of old and new infrastructures. As the institution has just celebrated her four decades of existence three years ago the need to conduct a research examining the environmental sanitation and its health hazard in this institution is a welcome development. This will determine her coping strategies in the annual incremental population. All Government had professed commitment to her preservation by the various funds from both the State and the Federal such as capital grants, stabilization and monthly allocation to keep the wheel rolling. The recognition of The Polytechnic Ibadan as Technical Institution and substantive Tertiary accorded her the following features:

1. It is a corporate or statutory body set up to perform special functions using the civil service procedures and encumbrances to carry out her function swiftly and efficiently.

2. The Polytechnic Ibadan as a body sees the need for decentralization of its authority and delegation of functions as variables to contest her performances and maturity over time.

3. As a place of dissemination and expansion of Technical knowledge. Traditionally it should be shielded from political influences, to retain the essence of research findings

4. Sometimes University and Polytechnic management are able to influence decision at the highest level as some of their personnel have been appointed as technical crew of Ministries and Parastatals. (Civil Service Reform 1958). 
The campaign for environmental sanitation has been launched severally, leading to emergence of various agencies like Federal Environment and Protection Agency (F.E.P.A), Ministry of Water and Environmental Sanitation, Solid Waste Management Authority and Local Community and Health Development. Many Private sectors are also involved in waste collection and processing in the urban areas. There is no doubt that huge funds and resources have been sunk on researches in various units of environmental sanitation in major commercial cities like Lagos, Ibadan, Kano, Port Harcourt, and Akure with problem arising at the implementation level. But while there were no tremendous positive result in cities an appreciable effect can be observed in most of the institution of higher learning in Nigeria. Thus necessitating the following questions that led to disparity in attention: What must have been responsible for this trend? Is it good problem perception or good policy initiation, formulation and implementation, or the value judgment of academia to life? Or is it their low population density? Then how can we sustain this good health habits or gesture to ensure that:

1. Academic people lead healthy and productive lives by waste and pollution control

2. The natural environment is protected and resorted to for absorption recycling and harmless rendering

3. The conservation and reuse of resources is encouraged in local level economic activities.

Foreign Literature showed many researches have been done, yet still need to be done in this area. Critical analysis of literatures gave the idea of reduce, reuse and recycle of all waste, effective cost and benefit analysis Almond (2001).Some researchers that are related to this work are Myen (1995) whose study on environmental exodus as an emergent crisis in global arena. Abdul (2001) concentrated on constructions of waste recycle process. Oludare (2002) researched into waste management in the construction industries; his work on safety evaluation for the improvement of occupational health is a pointer to human resources management. This study is a followed up to Omoleke's research on environment pollution in Ibadan (2005).

\section{Statement of the Problem}

Majority of studies on environmental sanitation in developing countries are outside the Institutions of higher learning. Outcome may be adopted due to unique feature in this close system as a result of greater awareness, normal population growth, lesser poverty ridden and the need to eradicate associated diseases Almond (2001). Given that the problem of environmental sanitation is like "Abiku" in the Nigeria context that responds little or none to treatment regardless of huge investment involved (men, material and money). Then why is it that all existing solution made little impact? Who are to be blamed for the failure of the constituted environmental sanitation? Scant availability of similar research in electronic or print format using Nigeria Polytechnics as case study necessitates this study.

\section{Objectives of the Study}

The objectives of the study are to:

1) Examine types and causes of pollution experienced by The Polytechnic, Ibadan .

2) Identify the strategy adopted by the institution to the challenges of the pollution; and

3) Analyze the effects of indiscriminate dumping of refuse in The Polytechnic Ibadan.

\section{Literature Review}

Extensive Research has been done in the field of Environmental Health in developed countries within and outside academic environment. Courses on environmental education abounds in their Institutions of learning leading to specialization like Environmental Chemistry and Microbiology, environmental Communication and Education, Environmental Law and Legal Assistance, environmental Engineering and Quality Control whose discipline may have the torch of Pharmacy (Earthwatch 2007) Foreign literature showed that remarkable amount of research on waste reduction, reusing, recycling, recovery and cost effectiveness. But the concentration of studies in developing countries is outside the Institutions of higher learning. In a work of this nature, it is not unusual to begin with definition to explain or define environmental sanitation from various concepts.. This will show a notable agreement on some attributes which are common to the various definition and explanation. Different government has variant of impact on people.

There is much impact on this programme by Nigerians that experienced and acted on the script of late Major Tunde Idiagbon's WAI policy that was launched in 1985. At the occasion that he said: Slum and ghettos were the incubators of epidemic diseases that pose serious threat to human health) (Free Library 2002). Environmental sanitation was defined as "The control of all those in man's environment which exercises a deleterious effect on his physical 
development" (Wordnet 2006).This definition will be more meaningful with Omoleke (2003) assertion that physical environment is a conglomeration of socio ecological and economical determination of how individual and nation responds to local and global issues. Wikipedia encyclopedia's definition is:

"Sanitation is the hygienic means of preventing human contact from hazards (which can be physical, microbiological/biological or chemical agents of diseases of wastes to promote health)".

The most recent and well fine tune is the Random House dictionary that goes thus:

"The development and application of sanitary measures for the sake of cleanliness, protecting health or the disposal of sewage and solid waste" (Random 2009).

Johnson (1994) had a critical observation of linking moral to sanitation and that unimproved sanitation amount to injustice. He therefore defined environmental injustice as:

"The disproportionate exposure off communities to pollution and its concomitant effect on health and environmental as well as the unequal environmental protection and environmental quality provided through laws, regulations and governmental programs enforcement and policies".

From these definitions, the notable agreement is that environmental sanitation has synonyms like Bill of Health $(\mathrm{B} / \mathrm{H})$, debt relief (Economic Sanity), environmental sanitation and moral justification. Also the centre of agreement is the state of being clean and being conducive to health (Wordnet2006). However, the fact that War against Indiscipline (WAI) target waste, mismanagement, corruption and environmental sanitation meant that the success and failure of environmental sanitation is a twin factor of both mundane and spiritual. The common understanding in terms of world view is a pointer to the importance of environmental sanitation.

\subsection{Importance Of Environmental Sanitation}

The success and importance of environmental sanitation cannot be divorced from the point highlighted below:

1. To reduce the occurrence of diseases and number of death tolls associated with poor hygiene.

2. To improve upon poor sanitation, inadequate toilets, lack of understanding about the importance of toilet and sanitation, current poverty level, and low level investment by all tier of governments and local communities.

3. To make government and the governed understand the concept of environmental sanitation and sustainability which is more of a journey rather than a stage to reach?

4. To bring a reversal to options of either you buy water or drink polluted one this can be done by having more toilets so that drinking water can be separated from waste water.

5. To make sure that there is sufficient and regular supply of safe water to all houses, offices and student hostels without any stress to guarantee well- being of students and staff.

\subsection{Disease And Environmental Sanitation}

W.H.O. in 1948 defined health as a state of complete physical, mental and social well-being and not merely absence of disease or infirmity. Thus WHO defined health not disease, however, Webster define disease as a discomfort, a condition in which bodily health is seriously attacked, endangered and impaired, a departure from a state of health, an alteration of human body interrupting the performance of vital functions. Therefore, an. environment is the sum total of habits, economy and society. This will embraces life support system of air, water, food shelter, and the multiplicity of provocative forces bearing down affecting his health. The author agree with Almond (2001) postulation that comprehensive exercise must take care of waste reduction, re-using, recycling and recovery as tagged $4 R s$. This is because this idea will bring both Cost Effectiveness Analysis (C.E.A) and Cost Benefit Analysis (C.B.A) for all the stakeholders.

\subsection{Summary of Reviewed Literatures}

Environmental Sanitation is a means to manage human waste at average cost, time and space. This will require the concern of many disciplines such as town planning, architecture, estate surveying, law, quality assurance and control, public health and human psychology. The involvement of many disciplines will amount to variants of agreements and 
disagreements which affects the beneficiaries without any exception. This author disagreed with WHO and UNICEF general recommendation of 20 litres of water per person per day. Areas of water usages are not always the same. as academic inhabitants usage are more than ordinary individuals as it includes watering of flower and vegetables, recreation and entertainment, ornamental decoration, sewage disposal, carrying out of laboratory tests and so on. This author equally disagreed with Zubair (2009) who sees sanitary surveying as support necessary for environmental health. As he opined that the need for identification of water quality are the only essentials for environmental sanitation and hygiene. But it is the inadequacy of environmental sanitation that is responsible for recurring of Ibadan flood disaster since 1948 till 2011( Babatunde et al. 2012) and (Adejuwon 2014) In addition, Nwogu (1999) looked at user's acceptance education as one of the factors influencing implementation of environmental sanitation. This author therefore sees this framework as a necessity to make meaningful decision in the life of academic community and beyond. Also a good deal of empirical research on recycling and re-using behaviour is imminent as a way out of separating usable items from real waste of no appreciable market value. The "Buy-Back" Concept of eliminating menace of paper/nylon waste, empty bottles, plastics, machines scraps and polythene related products in towns and cities is a testimony to this meaningful postulation. This is to create a new conservation and re-use culture in academic environment through various empirical researches that can be supported by International bodies, as it was done in Kenya and Nairobi. In these two countries used engine oil by vehicles were converted into cash, turning pollutant into an income supplements and encouraging mechanics to collect used oil instead of discharging it into the body of water (Environmental matters, 2005).

\section{The Polytechnic, Ibadan as a Case Study}

The available sources of water are water hawked around by school water tanker drivers, water factory for sachet and bottle, bore-holes and wells. The usage of water cover areas like washing, laundry cleaning, watering flower, drinking, cooking, sewage disposal, flushing and sanitation, fire fighting, construction and renovation. Therefore, the recommendation of WHO and UNICEF (2003) of 20 litres per person per day may not be adequate for most academic inhabitants.

\section{Research Methodology}

This study accomplished a general assessment of the attitude of The Polytechnic Ibadan Staff and Students to the Environmental Sanitation Agenda. This covers the scope, research design, and sources of data, method used to obtain and analyze data as well as design of instrument. This method is adopted in order to judge correct feeling of all the stakeholders on a matter of environmental management. This can be a fulcrum by which researcher s(and social scientist) can have access to information that is useful to formulate epistemological theories, hypothesis and research findings without a neglect to conceptual and cultural paradigms.

This research is associated with varying conditions such as beliefs, norms, values and practices that is non-static human culture, hence the methodologies has to be descriptive using combination of survey, personal interview and documentary inspection so as to have totality of human experience in knowledge development.

\subsection{The Case Study}

The research would be restricted to Ibadan Main Campus of The Polytechnic Ibadan. The group under study will be staff and students resident on campus. Also, the staff at the health center that provide training and monitoring for food vendors and those at Works Maintenance form the respondents. The role of work and services is to allocate space for all kiosks, shops and other physical planning in the institution. The students in higher National Diploma (in $1^{\text {st }}$ and $2^{\text {nd }}$ year) were also incorporated as respondents as they constitute part of beneficiaries. The entire population sample estimate is 120 staff, 130 students. All their responses will be analyzed to accomplish the stated objectives.

\subsection{Research Design}

The normative survey of research was used in collecting data for this study relevant literature was consulted for the development and construction of questionnaire. The questionnaires were structured into four divisions in this order:

Section A - Was based on personal information of respondents.

Section B - Was based on the importance of environmental sanitation. 
Section C - Discusses waste management

Section D - Focuses on environmental and health relation.

\subsubsection{Sources of Data}

The primary data was obtained by the use of questionnaire, Record inspection and interview were conducted at the Health Centre.to support the tool. Relevant information obtained from records in various units like Library and Registry among others. Materials consulted include textbook, journals, official publication and unpublished works. These were study for comparison, of ideas, and postulation on the management of the exercise in this institution.

\subsubsection{Organization of the Instrument}

The title page of the instrument carries an explanatory note in which the purpose of the study was clearly stated, and anonymity of replies were greatly assured. The questions were arranged in a logical order to sustain the interest of the respondents. The information requested in sections $B, C$ and $D$ were personalized as obtained in the literatures reviewed. The questionnaire consisted of four sections - Section A explored personal, educational background information of the respondent. Section B examined the importance of sanitation programme, section $\mathrm{C}$ concentrated on waste management and Section D examined the relationship between health and disease condition and the environment.

\subsubsection{Administration of Questionnaire}

The questionnaire was personally administered to staff of The Polytechnic Ibadan particularly senior staff from Health Center which is Nurses and Doctors, staff of Works and Services Unit that see to the effective implementation of on environmental sanitation Agenda and some Institution staff that are resident in the two staff quarters within ljokodo and North Campus quarters formed major respondents.

The researcher also visited the Health Centre to examine document on various cases that are related to water borne diseases, so also food canteens were also visited to find out how food sanitation concept are being followed by the operators. This is because the author belief that the danger can emanate from food service workers and managers who lacks adequate food handling skills.

\subsubsection{Methods of Collecting Data}

At the Polytechnic Ibadan questionnaire were distributed in this order: Two Hundred and Fifty questionnaires were administered in all. Thirty were administered at the Health Centre, this constitutes $12 \%$, Fifty (20\%) of questionnaire were administered at the Works and Services and Forty (i.e 16\%) were administered at the two staff quarters (ljokodo and North Campus). Thus One Hundered and Twenty (48\%) of the total questionnaire were administered to the staff. The students of HND I and HND II who are resident in the hostel were given the largest of the remaining questionnaire, female students were given seventy five (60\%) while male students were given fifty five (44\%) questionnaire of the remaining 52\%. Hall Warders were used for the administration of questionnaire to students to ensure maximum cooperation of the students during administration while the superior staff was used as the electrode between the investigator and the staff respondents. Therefore a response rate of One Hundred percent was recorded.

\subsubsection{Sampling Procedure and Sample Size}

The entire population was too big to study because of varieties off constraints but the sample under study was the true representation of the total population which the researcher is working on. The cluster sampling was the method adopted; the sample population were zoned and located separately along personal information such as sex, age, educational attainment, years of service and designation. The total sample of respondents is Two Hundred and Fifty in number which is highly infinitesimal when correlated with either student's staff population (of over Fifteen Thousand and Four Thousands respectively). 


\subsubsection{Method of Analysis of Data}

The variables were analyzed by means of percentages and simple table method. This technique permits inferences about observation and are useful for testing the research propositions for generalization the propositions were tested by descriptive statistical terms and detailed percentage was adopted for clear interpretation and presentation. Tables were adopted in order to create ease of understanding, lasting impression and quick comparison, easy summation of items and detection of errors and omissions.

\section{Findings of Results}

\subsection{Data Analysis and Discussion}

On discussion of this nature, the need to express the importance of examining background characteristics of individual to discover possible relationship between those variables of respondent on the environmental sanitation activities was understudied. The personality of respondents, the attributes or variables such as sex, age, academic qualification and year of service are hereby examined as a starting point.

\subsection{Sex Analysis of Respondents}

Table 1 shows the sex distribution of respondents, 120 (48\%) of the questionnaire were given to the staff, out of 120 (48\%) 85 were males and 35 females, while 130 (52\%) given to students with 75 being female and 55 male

Table 1: Sex Analysis of Respondents

\begin{tabular}{|c|c|c|c|}
\hline & Sex & No. of Respondents & Percentage \\
\hline \multirow{2}{*}{ Student } & Male & 55 & 22 \\
\cline { 2 - 4 } & Female & 75 & 30 \\
\hline \multirow{2}{*}{ Staff } & Male & 85 & 34 \\
\cline { 2 - 4 } & Female & 35 & 14 \\
\hline \multirow{2}{*}{ Total } & & $\mathbf{2 5 0}$ & $\mathbf{1 0 0 . 0 0}$ \\
\hline
\end{tabular}

Source: Field Survey 2013

\subsection{Age Analysis of Respondents}

Table $2 \mathrm{a}$ and $2 \mathrm{~b}$ is a display of age distribution of the respondents. The staff in the population sampled range from age 25 to 55 , while the students ranged from 20 to 35 . The average age of staff respondents lies between 36 and 45 and that of students is between 20 and 25. This therefore means that both students and staff respondents are young adults who are highly useful for national developments. Their vigour and vitality will allow initiative and innovation to be created and adopted. They are also within potential group for continuous development to meet future changes, social, economic and technical adjustment.

Table 2a: Age Analysis for Students Respondents

\begin{tabular}{|c|c|c|}
\hline Ages & Respondents & Percentage \\
\hline Students Under 20 & 14 & 5.6 \\
\hline $21-25$ & 50 & 24.0 \\
\hline $26-30$ & 35 & 14.0 \\
\hline $31-35$ & 21 & 8.4 \\
\hline Total & 130 & $\mathbf{5 2 . 0}$ \\
\hline
\end{tabular}


Table 2b: Age Analysis for Staff Respondents

\begin{tabular}{|c|c|c|}
\hline Ages & Respondents & Percentage \\
\hline Staff Under 25 & 19 & 12.0 \\
\hline $26-35$ & 25 & 10.0 \\
\hline $36-45$ & 55 & 22.0 \\
\hline $46-55$ & 21 & 8.4 \\
\hline Total & 120 & $\mathbf{4 8 . 0}$ \\
\hline
\end{tabular}

Source: Field Survey 2013

Absolute Total $=120+130=250$ And $52.0+48.0=100 \%$

\subsection{Academic Qualification of Respondents}

Data presented in table 4 elicited the staff participants' qualification as all students belong to Higher Diploma category H.N.D. It was found that (54) $60 \%$ of the staff has H.N.D. This was the commonest qualification for all residents' staff in the polytechnic and probably if the institution has start running bachelor of Technology as it is in the proposal. All these staff or some of them might have gone for further training and development in various disciplines. $10 \%$ of the staff (12) has higher degrees such as masters or equivalent to such as medical doctors, senior nurse and supervisors of environmental sanitation within the work and service unit of the institution. Some of them have gone to short term course at school of Hygiene, Eleyele, Ibadan. They are no more than $25 \%$ of population. They are possessor of diplomas, trade test and these are staff that are directly involve in the cleaning and control of any pollutions within the institution.

Table 2b: Age Analysis for Staff Respondents

\begin{tabular}{|c|c|c|}
\hline Qualification & No of Respondent & Percentage \\
\hline HND & 54 & 45.0 \\
\hline Bachelor & 12 & 10.0 \\
\hline Master & 24 & 20.0 \\
\hline Others & 30 & 25.0 \\
\hline Total & 120 & 48.0 \\
\hline
\end{tabular}

Source: Field Survey 2013

\subsection{Years of Service at the Institution}

The students were not involved as this question seemed to be irrelevant since all of them belong to the same category with a slight variance in Matriculation year. With regards to experience in the service of the institution $24(20 \%)$ of the respondents staff have spent the least range of 1-8 years, $36(30 \%)$ of the staff have their range of service between 9-16 years, $40(33.33 \%)$ falls within $17-24$ years and $20(16.66 \%)$ were above 24 years in service.

From the above breakdown one can deduce that $60(50 \%)$ of the staff are within 1-16 years of experience in the service. Both the Modal and the Median class are also within this end. This is an indicator that most of these staff can still be trained as they are young and will be ready for any innovative change in the maintenance and survival of the institution. Another interesting thing in the analysis is that $76(66.33 \%)$ of the staff also falls within the category of 9-16 and 17-24 years of service. This category can equally be useful for supervisory role in areas of waste treatment such as processing and converter for fertilizer and other organic or chemical materials that can serve as input for plant.

Table 4: Years of Service of Respondents

\begin{tabular}{|c|c|c|}
\hline Age Range & No of Respondent & Percentage \\
\hline $1-8$ & 24 & 20.00 \\
\hline $9-16$ & 36 & 30.00 \\
\hline $17-24$ & 40 & 33.33 \\
\hline Above 24 & 20 & 16.67 \\
\hline Total & 120 & 100.00 \\
\hline
\end{tabular}

Source: Field Survey 2013 


\subsection{Research Question 1}

Are you aware of any research in environmental sanitation in this institution?

Both the staff and students said NO" which is a confirmation that as of the time of this investigation both staff and students has no knowledge of this type of research in any Polytechnic institution in Nigeria whether in print or electronic format. It is a confirmation that it is a dry area and worth venturing in order to have a reference point for future fields works.

\subsection{Research Question 2}

What are the reasons for considering environmental sanitation as important?

Four options were provided for respondents: $95(38 \%)$ of the respondents choose the option of safety and hygienic condition as the reason behind the programme. $35(14 \%)$ of the respondents choose job opportunity as an important reasons for carrying out environmental sanitation exercise 75 (30\%) of respondents felt that sustainable development and maintenance of culture and social value option is needed by everybody. While the remaining 45 (18\%) consider safety at work as an option. On examining the four options, the first and the third options are in line with the nature of men that put safety and hygienic condition couple with societal and cultural values over other benefit of sanitary exercise. When the percentage of these options is considered over the remaining option, there is a large difference between $68 \%$ and $32 \%$. See the Table below

Table 5: Reason for the Importance of Environmental Sanitation

\begin{tabular}{|c|c|c|}
\hline Options & No of Respondent & Percentage \\
\hline To ensure a safe and hygienic condition & 95 & 38.00 \\
\hline To provide job & 35 & 14.00 \\
\hline To retain cultural value & 75 & 30.00 \\
\hline Safety at work & 46 & 18.00 \\
\hline
\end{tabular}

Source: Field Survey 2013

\subsection{The Polytechnic Community Water Needs}

Apart from others that were specified, twelve direct uses of water were identified. Water is used for washing (100\%), laundry (100\%), cleaning (100\%), drinking (100\%), cooking (100\%), preparation of food and beverages (100\%). A respondent is allowed to pick more than one usages see table 6. Others are for decoration and ornamental purposes $88.51 \%$, fire fighting (72.11\%), sewerage disposal (100\%) and in flushing and sanitation (100\%) recreation and entertainment for example in swimming pool (58.25\%), $80 \%$ use water to maintain the ornamental plants (grasses and flower particularly in the dry season) when rainfall and dews will be minimal (if any), $33.12 \%$ use water in construction and reconstruction and veneration.

Without mincing words water is therefore very salient to survival and it is life wire of the academic community as table 6 shows. But the next question is on the sources of water consume in the Polytechnic as well as the level of satisfaction derived from the supplies. As earlier mentioned in the literature review the sources of water include rainfall, wells, public pipe water which is epileptic, bottled and sachet water and water hawked around by the school water tanker. Some occasion may warrant some few students and some staff to fetch water from Oba dam extension. If these are various sources of water then how do we get to the level of satisfaction of this community? Likert scale was used to describe the level of satisfaction. It ranges from very poor level of satisfaction to excellent (outstanding). Excellent (outstanding) level of satisfaction was expressed by only 25 respondents (10\%). 
Table 6: Age Analysis for Staff Respondents

\begin{tabular}{|c|c|c|}
\hline Option & No of Respondent & Percentage \\
\hline Washing & 250 & 100.00 \\
\hline Laundry & 250 & 100.00 \\
\hline Cleaning & 250 & 100.00 \\
\hline Watering flower and vegetable & 200 & 80.00 \\
\hline Recreation and entertainment & 145 & 55.00 \\
\hline Drinking & 250 & 100.00 \\
\hline Cooking & 250 & 100.00 \\
\hline Beverages and drinks processing & 250 & 100.00 \\
\hline Sewerage Disposal & 250 & 100.00 \\
\hline Flushing and sanitation & 250 & 100.00 \\
\hline Fire fighting & 180 & 72.00 \\
\hline Construction/renovation & 85 & 34.00 \\
\hline Ornamental decoration & 225 & 90.00 \\
\hline Others specified & 100 & 40.00 \\
\hline
\end{tabular}

Source: Field Survey 2013

Table 7: Level of satisfactory Water Supply

\begin{tabular}{|c|c|c|c|c|}
\hline Level of satisfaction & No of Respondents & \% Proportion & \% Cumulative & Inverse umulative \\
\hline Excellent & 25 & 12.0 & 10.0 & 100.0 \\
\hline Very satisfactory & 36 & 14.4 & 24.4 & 90.0 \\
\hline Satisfactory & 39 & 15.6 & 40.0 & 75.6 \\
\hline Fairly satisfied & 25 & 10.0 & 50.0 & 60.0 \\
\hline Poor & 75 & 30.0 & 80.0 & 50.0 \\
\hline Very Poor & 50 & 20.0 & 100.0 & 20.0 \\
\hline Total & $\mathbf{2 5 0}$ & $\mathbf{1 0 0 . 0}$ & 100.0 & 100.0 \\
\hline
\end{tabular}

Source: Field Survey 2013

Only $24.40 \%$ which is less than one-quarter of the total respondents were very satisfied with the supply situation, while only just $40 \%$ got some level, of satisfaction as Table 7 indicated. As much as 50\% expressed poor level of satisfaction "very poor" poor and fairly satisfactory are the level of satisfaction expressed by $60 \%$ of the respondents. Specifically on interview, the respondents remarked bitterly on the water irregularities. Hence so much have to be spent to get good quantity and quality individually. Definitely inadequate and unsatisfactory levels of water supply are the limitations to the full realization of the satisfactory comfort, efficiency and efficacy of environmental sanitation in the Polytechnic. This can not be ruled out of the quantity and quality of human and material resources on ground and the inadequacy of allocation to the environmental maintenance by the school management.

\subsection{Waste Management}

In this segment, various research questions were raised. One of the questions is on categorization of waste generation. It was realized during the survey that the population size is directly proportional to the waste generated across the whole areas. While the students' hostels generated the highest domestic/organic and the school areas have the least, due to differences in population density of the poles. The economics status of all the resident staff in the staff quarters of this institution has made it possible to consume more, leading to incremental waste generation because of similarity in status. Every dumpsite is experiencing increment than before while less of it was being assimilated. The left-over eventually constituted the environmental pollution. However the human inspection of various dumpsites led to the categorization. 
Table 8: Categories of Waste Generated

\begin{tabular}{|c|c|c|}
\hline Types & No of Respondent & Percentage \\
\hline Garbage & 84 & 33.6 \\
\hline Rubbish & 54 & 21.6 \\
\hline Ashes & 58 & 23.2 \\
\hline Bulky Waste & 36 & 14.4 \\
\hline Special Waste & 18 & 7.2 \\
\hline Total & $\mathbf{2 5 0}$ & $\mathbf{1 0 0 . 0}$ \\
\hline
\end{tabular}

Source: Field Survey 2013

The analysis of wastes generation will assist in its management. Therefore the break down as shown in the table goes thus. Garbage $84(33.6 \%)$ is food remnants that attracts rodents and insects While rubbish $54(21.6 \%)$ are vegetable peeling. food package and garden rubbish. The two can be referred to as agro allied wastes $(84+54)=138(55.2 \%)$. Ashes $58(23.2 \%)$ is the bye - product of domestic combustion of solid fuel open burning generated by food vendors. Bulky waste constitutes 36 (14.4\%) which are unwanted appliances such as refrigerator, radio, furniture's among others, special waste 18 (7.2\%) are hazardous items which are toxic, chemicals, biologic or infectious wastes are the least of all types in this institution. Closely following these types of the wastes is this question. Which areas generate the highest waste in this institution?

Table 9: Age Analysis for Staff Respondents

\begin{tabular}{|c|c|c|}
\hline Areas & No of Respondent & Percentage \\
\hline Health centre & 211 & 8.40 \\
\hline Students hostel & 85 & 34.00 \\
\hline Business centre & 75 & 30.00 \\
\hline School areas & 14 & 5.60 \\
\hline Staff quarters & 55 & 22.00 \\
\hline Total & $\mathbf{2 5 0}$ & $\mathbf{1 0 0 . 0 0}$ \\
\hline
\end{tabular}

Source: Field Survey 2011

The highest waste generation areas are student's hostel 85 (34\%), business centres 75 (30\%) and staff quarters 55 (22\%), and these areas contains greater percentage of open dumps leading to deplorable conditions of public hygiene and sanitation. The least generated points are school areas 14 (5.6\%) and Health centre 21 (5.40\%). The highest in the former can be linked to massive population growth in the area over the latter. This is in line with Brown (1993) that population growth, and economic prosperity has reflection on waste generation. Policies and programmes must be restructured to maintain the least generation and improve upon the highest.

\subsection{Method of waste disposal}

For any appreciable progress in waste management, prevention of health hazards is very essential. Therefore careless handling and improper collection schemes for waste must be overhauled. .There are four methods of waste disposal at The Polytechnic Ibadan, these are dumping and compositing, dumping and burning, transportation and deposition outside the school and others such as gifts / donation, exchange and sales meant for re-use are rare. Dumping and compositing factor account for $58(23.20 \%)$ respondents. While $112(44.80 \%)$ of respondents beliefs and adopt dumping and burning as the appropriate methods of waste disposal. 
Table 10: Method of Waste Disposal

\begin{tabular}{|c|c|c|}
\hline Options & No of Proportion & Percentage \\
\hline Dumping and compositing & 58 & 23.20 \\
\hline Dumping and Burning & 112 & 44.80 \\
\hline Transportation outside the school & 51 & 20.40 \\
\hline Any others & 29 & 11.60 \\
\hline Total & 250 & 100.00 \\
\hline
\end{tabular}

Source: Field Survey 2013

\section{Conclusion}

This study examines the environmental sanitation and its health hazards in The Polytechnic Ibadan. It is evident that the programme is in place even if the achievement recorded has not reached the level recommended by the three world bodies which are WHO, UNICEF and UN-HABITAT. The success recorded so far in its practice can be linked to the policy guidelines that were conceived at the inception of programme and how it has been handled till date. The need for correction on this concept has been subjected to various thoughts, Impressions and beliefs, as changes are inevitable in human lives. It is human dynamism that has made the importance of environmental sanitation programme to be reviewed to accommodate the following:

Reduction of health hazard inform of sickness and deadly diseases like cholera, Ebola and malaria that can be linked to unhygienic environment.

Improvement upon the present sanitation programme by the introduction of vaccines and antiviral as preventive measures,, increment on the existing facilities such as equipment, trucks, water supply, toilet and personnel . Creation of concept where all stake holders will participate so that the Sustainability of the programme will become a journey rather than stage to reach.

The environmental sanitation is a global issue and the problem emanated from it is always complex. It is therefore advisable that environmental health scientist must participate in all facet of the programme right from policy debate down to the evaluation level.

\section{Recommendation}

W.H.O sees the disposal of human waste as the essence of environmental sanitation and environmental health. The executive administrators should organize seminars and workshops on faculty and departmental basis on this. Also more researches should be sponsored to effectively educate the inhabitants on the need to improve and sustain environmental sanitation programme for the purpose of healthful living. More health workers should be saddled with talks and counseling for people when they attend Health Centre for consultation under the dictum 'The more hygienic a community is, the healthier they become'. There is need for impromptu inspection around the campus from time to time in order to avert disease breeding space if any.

More toilets should be put in place in strategic locations to complement the existing ones to reduce incessant urination and faecal deposit at undesignated areas. Waste disposal vehicles and allied equipments should be procured so that waste can safely be removed from the institution on schedule basis and partnership with private agencies should be established to convert waste to wealth through reduce, reuse and recycle system.

The management of the Polytechnic Ibadan should source for more funds from local and international level so that all the listed items above can be carried out successfully. From the foregoing these issues should be given necessary consideration for the prevention of human contact from hazardous effects.

\section{References}

Abdul A.I. and Ahmed S. (2001). Pollution problems and control in factory environment in Nigeria. Namoda Tech Scope Journal of Applied Science and Technology, vol. 4(2)

Adejuwon G.A and Aina W.J (2014), Emergency preparedness and response to Ibadan flood disaster 2011: implications for wellbeing, vol. 5(8).

Almond C. (2001). Construction of Waste Recycling Process, Research Report, Victoria BC. 
Business Dictionary (2010)

Babatunde S.A, Owolabi A, Olalekan J.T and Bolanle W.W (2012), The august 2011 flood in Ibadan, Nigeria: Anthropogenic causes and consequences. Int.J. Disaster Risk Sci. 2012, 3(4).

Brown D.T. (1993). The legacy of landfills in Mustafa, N. (ed) plastics waste management disposal, recycling and reuse. Marcel Dekker Publishers, Inc. New York.

Earthwatch (2007). Environmental Carer. Earthwatch Nigerian Magazine for Environment and Development, Port Harcourt, Nigeria.

Environmental Matters (2005) Annual Review World Bank. Washington D.C

Sanitation (2009) Wiki-Media Foundation

Federal Ministry of Environment. (Federal Ministry) (1991).Guidelines and standard for environmental control in Nigeria.

Hassan, Arif (1999). Understanding Karachi: Planning and reform for the Future. City Press Karachi.

Myen, N. (1995) Environmental Exodus: 'An emergent crisis in the global arena' Washington D.C Climate Institute, USA

Omoleke, I.I. (2005). Environmental pollution and its health hazards in Ibadan, Nigeria. African Journal of Nursing \& Midwifery, vol. 7 (2) pp 35-50

Quraeshi, A.F and Lobo, M.A. (1991). Socio-anthropological determinants and home managements of Karachi Pakistan. Journal of Tropical Paediatrics Vol. 40

Random House Unabridged Dictionary (2009). Random House Inc.

Sustainable sanitation (2008). Wikipedia

Worldnet (2006) Princeton University. 